\title{
A REFERENCIAÇÃO NA LÍNGUA BRASILEIRA DE SINAIS
}

\author{
Leidiani Da Silva Reis \\ Universidade Estadual do Oeste do Paraná \\ Conselho Nacional de Desenvolvimento Científico e Tecnológico
}

Title: The reconstruction of discourse objects in Libras

Abstract: This work analyses the referential process performed by a deaf subject in Brazilian Sign Language (BSL) when facing the anaphoric occurrence in a textual cut from Brazilian Portuguese. Therefore, the methodology implemented hereby has had a qualitative nature. A parallel corpus has been compiled using ELAN (EUDICOLinguistic Annotator) and following the theories of Corpus Linguistics. From all the referential categories contemplated in BSL, the anaphoric deictic has been the most instrumental strategy for conducting the referential chain of the language, e.g. the construction of the referent at specific points in the signalling space.

Key words: Referential process. BSL. Reconstruction of discourse objects. Anaphoric deixis. Parallel corpus Portuguese-BSL, translation.

\section{IntroduÇão}

As línguas de sinais são sistemas criados e produzidos no plano visuoespacial. São línguas naturais das comunidades de surdos e, foram criadas espontaneamente, por eles próprios. É um símbolo da identidade, um dos elementos culturais do sujeito surdo (SLOMSKI, 201 2). No que diz respeito ao Brasil, a língua falada pela comunidade surda é a Libras. Apesar de há muito tempo ter sido assumida pelos surdos como a sua língua natural e, portanto, o principal meio de comunicação e expressão da comunidade, foi somente em 24 de abril de 2002, com a publicação da Lei n ${ }^{0}$ 10.436, regulamentada pelo Decreto n 5.626, que se tornou a segunda língua oficial no país. O fato de ser uma língua visuoespacial, modalidade bastante distinta da Língua Portuguesa (língua oroauditiva), vem abrindo um leque de possibilidades de pesquisas avançadas, principalmente no campo da Linguística. Nesse contexto, estudar os processos e os mecanismos linguísticos envolvidos na Libras tem sido um desafio e, ao mesmo tempo, um caminho promissor para as investigações científicas. Dos diversos fenômenos linguís- 
ticos observados na referida língua, a Referenciação foi a eleita, tendo em vista seu uso frequente durante a elaboração discursiva.

Nesse sentindo, adotamos, nessa pesquisa, a Referenciação a partir de uma abordagem sociocognitivointeracional da Linguística Textual, que toma tal processo como uma atividade discursiva, e se direciona no sentido de "pensar o texto como lugar de constituição e de interação de sujeitos sociais, como um evento, portanto, em que convergem ações linguísticas, cognitivas e sociais" (KOCH, 2002, p. 9), ações por meio das quais se "constroem e reconstroem interativamente os objetos do discurso e as múltiplas propostas de sentidos, como funções de escolhas operadas pelos co-enunciadores entre as inumeráveis possibilidades de organização textual que cada língua oferece" (ibidem, p. Io).

Apesar da complexidade envolvida no modo como se manifestam e na forma como se relacionam os itens que tomam parte do processo de Referenciação, avanços significativos já podem ser percebidos no âmbito das línguas orais. $\mathrm{O}$ mesmo não se pode afirmar em relação às línguas de sinais em geral, e em particular no que diz respeito à Libras. Na prática, quando pensamos, por exemplo, na relação entre o Português Brasileiro e a Libras diante dos elementos referenciais - nesse trabalho, selecionamos a anáfora direta como o fenômeno de partida -, num viés tradutório, podemos inferir que há complexidades e singularidades que denotam diferenças relevantes quanto à operação linguística referencial. Nesse contexto, Ferreira Brito (2010, p. i s) diz que "Referência em Libras funciona de maneira similar àquela das línguas orais, tais como o Português. Entretanto, (...), observa-se algumas especificidades que, provavelmente, são devidas à modalidade espaço-visual de língua".

Ao considerar as discussões elencadas, pretendemos responder às seguintes indagações: (i) À luz da teoria da Referenciação, como a anáfora que se realiza na Língua Portuguesa ocorre na Libras, considerando-se a dife- 
rença de modalidade entre as duas línguas? (ii) Acontece na Libras outras categorias de elementos referenciais diferentes das que ocorrem na Língua Portuguesa? (iii) Quais as estratégias utilizadas na Libras para a manutenção/ou não da anáfora? Mais exatamente, com esse trabalho objetiva-se verificar, mediante o viés teórico da Referenciação, o processo referencial realizado pelo sujeito surdo na Libras diante da ocorrência de anáfora direta em recorte textual do Português Brasileiro. Nesse conjunto reflexivo, assumimos como metodologia a pesquisa de cunho qualitativo, pautada numa perspectiva de revisão bibliográfica, documental e de campo.

2. ReFEREnCIAÇÃo: Um PROCESSO DE RECONSTRUÇÃo DE OBJetos DO DISCURSO

As autoras Mondada e Dubois (1995) vão contra as concepções que veem o processo de referir como uma relação especular língua-mundo, nas quais as coisas da realidade já existem e a função dos sujeitos é apenas nomeálas por intermédio da língua. Assim sendo, as precursoras propõem o termo Referenciação para expressar a ideia do dinamismo que envolve o processo, no qual se dá uma construção de objetos cognitivos e discursivos na "intersubjetividade das negociações, das modificações, das ratificações, de concepções individuais e públicas do mundo. (...) Essa abordagem implica (...) um sujeito sociocognitivo mediante uma relação indireta entre os discursos e o mundo" (MONDADA; DUBOIS, 2003, p. 20).

Numa visão ainda mais moderna da Referenciação trazemos os estudos de Ciulla (2008), a qual diz que a Referenciação é um processo que depende de uma série de atividades cognitivas e sociais que se estabelecem no momento da interação. Nessa perspectiva, entendemos que a formação de tais objetos do discurso é influenciada por fatores culturais, históricos, sociais, ou seja, pelo contexto de comunicação e não apenas por experiências individuais ou por meras reproduções pré-existentes da realidade. Além disso, conforme Leal, “os objetos do discurso são itens linguísticos dinâmicos, 
podendo ser modificados, desativados, reativados no curso da progressão textual" (LEAL, 20 I I, p. 46).

Como o objetivo desse trabalho é analisar, na perspectiva teórica da Referenciação, os processos referenciais realizados por sujeitos surdos na Libras diante das ocorrências de anáforas diretas em recortes textuais da LP, é importante cotejarmos sobre a anáfora, a qual tem sido constantemente debatida entre pesquisadores da área. Na perspectiva teórica sociocognitivainteracional do processo referencial, autores como Apothéloz (2003), Apothéloz e Reichler-Béguelin (1999), Koch e Marchuschi (1998), Mondada e Dubois (2003), Cavalcante (2O I I), Ciulla (2008), Colamarco (2O I4), Morais (2017), Santos e Cavalcante (2014), entre outros, consideram que a anáfora se constitui no interior do discurso como uma atividade colaborativa de interação entre os sujeitos. Nesse sentido, o sujeito, a partir da ativação de um objeto do discurso, com objetivos bem definidos, seleciona uma anáfora com a qual constrói a sequência de sentido de seu enunciado. Essa sequência permite a esse sujeito manter informações conceituais referentes ao tema sobre o qual está discorrendo. Para Morais (2017), "a escolha de determinadas anáforas está intimamente relacionada às representações e papeis sociais, aos propósitos comunicativos dos enunciadores e ao próprio sentido que se deseja atribuir ao texto" (MORAIS, 2017, p. 44). Assim, a anáfora se caracteriza como um dos processos fundamentais da Referenciação. Tanto é verdade que, segundo Koch e Marcuschi (1998), "a retomada anafórica é a estratégia de progressão discursiva mais estudada e conhecida, mas não de todo compreendida e provavelmente mal compreendida" (KOCK; MARCUSCHI, 1998, p. 76).

Conforme já mencionado, para esse trabalho selecionamos, como fenômeno de partida, as anáforas diretas as quais podem acontecer nas retomadas por pronomes (de ordem gramatical, anáfora pronominal) ou por formas nominais (de ordem lexical). Ocorrendo por formas nominais, o re- 
ferente pode ser recuperado por meio da repetição - parcial ou total -, por meio de sinônimos ou quase sinônimos, por meio de hiperônimos, por meio de nomes genéricos, por meio de descrições nominais, entre outras possibilidades. Nos dois primeiros casos de formas nominais destacados, têm-se a correferência sem recategorização dos referentes; nos três últimos, por sua vez, há uma recategorização do antecedente textual (KOCH, 2005). Por conseguinte, em uma retomada direta por formas nominais "pode haver simplesmente correferência entre a expressão anafórica e seu antecedente textual, ou ocorrer a recategorização deste” (KOCH, 2005, p. 264). A figura 2 representa a distribuição das anáforas diretas por formas nominais referenciais:

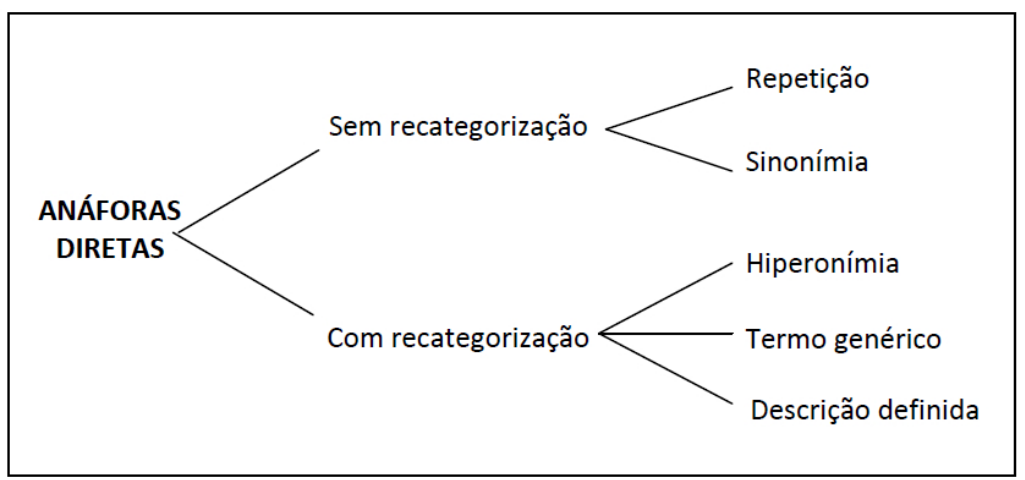

Figure I: Formas nominais referenciais( Fonte: Colamarcao, 2014, p. I34, adaptado de Silva; Ferreira, 2008).

3. O PROCESO REFERENCIAL NO ÂMBITO DA LÍNGUA VISUOESPACIAL

Diferentemente das línguas faladas, que são organizadas pelo aparelho fonador e percebidas pela audição, as línguas sinalizadas são articuladas pelas mãos e notadas pela visão, em outras palavras, são visuoespaciais. William Stokoe (1960) foi o primeiro a reconhecer e descrever o padrão fonológico, bem como morfológico de uma língua de sinais, especificamente, American Sign Language (ASL). Após a iniciativa desse linguísta escocês que vivia e trabalhava nos Estados Unidos, a pesquisa sobre ASL e outras lín- 
guas de sinais começaram a florescer, nos anos i 970 e i 980. Surgiram então os primeiros trabalhos voltados para o processo referencial, entre eles destacamos, por exemplo, o trabalho de Friedman (1 975, p. 940), em que a autora faz uma explanação de como a "visual language allows for deictic and anaphoric locative, temporal, and 'pronominal' reference”. Logicamente, essa é uma discussão bem inicial sobre como os processos referenciais, anáfora e dêitico, dialogam entre si, considerando a modalidade visuoespacial. Apesar de ser incipiente, representa a situação geral do estudo da "referência I" nas línguas de sinais, daquela época.

Destacamos também o estudo de Bühler (I 979), o qual também elencou a relação entre a dêixis e a anáfora, numa perspectiva referencial produtiva: "el contexto de un decir, que se va haciendo, se eleva él mismo a campo mostrativo, cuando indicamos anafóricamente" (BÜHLER, I 979, p. I42). Em outras palavras, o significado textual vai se consolidando à medida em que há o uso desses processos referenciais em conjunto. Outros pesquisadores em destaque são Bellugi e Klima (1982), os quais realizaram um estudo para identificar os termos dêiticos na ASL e constataram que tais termos formam a base do processo referencial, da concordância verbal e das relações gramaticais.

Apesar de já ter passado algumas décadas, essa é uma discussão que tem interessado muitos estudiosos atuais, entre eles apontamos, por exemplo, Philippe Schlenker (20I6), que buscou observar a relevância do espaço e do apontamento na construção anafórica. Segundo o autor, "the sign language anaphora is often realized very differently from its spoken language. An antecedent is associated with a position or 'locusin signing space, and an anaphoric link is obtained by pointing towards that locus to recover its semantic value" (SCHLENKER, 2016, p. 2, grifo nosso).

${ }^{\text {I} D e s t a c a m o s ~ e s s e ~ e l e m e n t o ~ m e d i a n t e ~ a s p a s, ~ p o r q u e, ~ n a ~ p e r s p e c t i v a ~ a d o t a d a ~ n e s s e ~ t r a-~}$ balho, o termo utilizado é Referenciação. "Referência" caracteriza a abordagem teórica adotada pelo autor. 
Diante desse contexto, para nosso estudo, trazemos, em especial, uma proposta analítica aplicada em American (ASL), French (LSF) e Italian (LIS) Signed Languages, de Pizzuto et al. (2006), em que os autores apresentam o dêitico enquanto componente do processo anafórico. Eles discutem sobre os fatores específicos das línguas de sinais que afetam a construção do dêitico-anafórico. Em outras palavras, os pesquisadores definem as estruturas dêitico-anafóricas como recurso de coesão textual que permitem a falantes ou sinalizantes mostrar (dêixis) e retomar (anáfora) referentes no discurso, simultaneamente.

A partir de uma análise comparativa de narrativas sucintas produzidas na $A S L, L S F$ e LIS, a pesquisa proporciona evidências importantes sobre o processo referencial nas três línguas de sinais. Mais especificamente, os dados analisados permitem avaliar a influência das relações entre as línguas a respeito dos referidos fenômenos investigados. Os autores propõem duas grandes classes de dêitico-anafóricos, nas línguas visuoespaciais:

I. Classe 'padrão', realizada por meio de apontações manuais e visuais, que estabelecem posições marcadas no espaço (os 'loci'). Nessa classe os referentes podem ser simbolicamente atribuídos. Alguns fatores são relevantes para o processo anafórico nessa classe, entre eles destacamos i) a direção do olhar: a anáfora ocorre com a marcação acentuada da direção dos olhos; ii) a soletração (datilologia): o pronome chama a atenção do interlocutor para a soletração, e a relação entre a soletração e o objeto referido é de inferência. Vejamos o exemplo: <ELA M-AR-I-A >; e iii) a locação: apontamento direcionado no espaço.

2. A classe de complexas unidades manuais e não-manuais, que não são sinais de apontação nem podem ser classificadas como sinais padrões. Essas unidades apresentam características altamente icônicas - denominadas Estruturas Altamente icônicas (EAI) ou 'Transferenciais' - e 
são marcadas por padrões específicos do olhar, por formas manuais que codificam atributos perceptíveis salientes das relações entre o referente e o elemento referencial (Classificadores ${ }^{2}$ ) e por expressões faciais marcadas e/ou modificações da cabeça, dos ombros e do tronco, tipicamente identificadas como 'recursos de troca de papeis'.

Conforme a análise desses autores, as línguas de sinais oferecem duas maneiras de produzir significado: "dizer sem mostrar", por meio do léxico padrão e da apontação; e “dizer e mostrar”, utilizando-se as EAIs.

In SL, unlike in verbal languages, there are two ways of signifying: either by 'telling and showing', thereby producing HIS or 'Transfers' that are unique of the signed modality, or by 'telling without showing', using the standard lexicon and pointings, and producing structures that are more comparable to those found in verbal languages (PIZZUTO et al., 2006, p. 478).

Explicam eles que essas duas formas consistem na opção consciente do sinalizante em ilustrar ou não o que diz. Supomos, então, que esses elementos sejam mais que ilustrações. Consideramo-los, com base nas discussões de Pizzuto et al. (2006), como objetos do discurso construídos no espaço físico, para serem retomados por meio do dêitico-anafórico: “These two ways of signifying mirror two different intents a signer can deliberately choose for articulating his/her discourse: an illustrative and a nonillustrative intent (and the resulting structures they produce) are defined 'Transfers'” (PIZZUTO et al., 2006, p. 479).

As EAIs são concebidas como vestígios de operações cognitivas por meio das quais os sinalizantes transferem sua concepção do mundo real para o mundo tetradimensional do discurso sinalizado (as três dimensões do espaço acrescidas da dimensão tempo) (PIZZUTO et al., 2006).

Nessa perspectiva, Felipe (2006, p. 206) corrobora que devido à modalidade visuoespacial, as línguas de sinais podem "introduzir, no contexto

${ }^{2}$ Nesse contexto, os Classificadores são caracterizados pelo ato de dizer e mostrar iconicamente ao mesmo tempo/ilustrar o que se diz. 
discursivo, a mímica e por isso um objeto, uma qualidade de um objeto, um estado, um processo ou uma ação pode 'mimeticamente' ser representada juntamente com a estrutura frasal”. Para o autor, esse "processo mimético transforma a mímica em uma forma linguística que representa iconicamente o referente a partir dos parâmetros de configuração sígnica e da sintaxe da língua” (FELIPE, 2006, p. 206). Diante disso, Cuxac (2000) diz que:

[...] tous Sign Language exploiter la capacité de base qui ont sinalizantes iconizar votre expérience perceptive / pratique du monde physique. Un effet de ce processus de iconisation est de fournir le langage des signes supplémentaires dúne sémiotique concernant les langues verbales (CUXAC, 2000, p. I 5$)$.

Segundo Pizzuto et al. (2006), diferentes subtipos de EAIs podem ser combinadas entre si, ou com sinais padrão, para codificar simultaneamente informações referentes a dois - ou até mais - referentes, permitindo uma especificação multilinear da referencia dêitico-anafórica, especificidade da modalidade visuoespacial.

Essas classes, 'padrão' e 'de complexas unidades manuais e não-manuais', foram amplamente detectadas nas línguas de sinais estudadas, por essa razão, podem representar uma das características que distanciam essas línguas das línguas oroauditivas. Conforme Pizzuto et al. (2006), elas são, aparentemente, muito semelhantes em várias outras línguas de sinais do mundo, o que torna plausível supor que elas sejam estruturas universais ou quase universais.

Por considerar o estudo dos referidos pesquisadores altamente relevante, buscaremos aplicar sua proposta, num viés da Referenciação, pois acreditamos que, quando a pessoa surda escolhe um determinado tipo de dêitico-anafórico no processo discursivo, ela não o faz aleatoriamente, ao contrário. Consideramos, também, a classe de complexas unidades manuais e não-manuais, caracterizadas por estruturas altamente icônicas muito mais 
que um elemento de coesão, ela é a representação do processo de Referenciação nas línguas de sinais.

\section{Percurso metodológico}

A metodologia adotada para a realização do trabalho é de cunho qualitativo, pautada numa perspectiva de revisão bibliográfica, documental e de campo. Assim sendo, houve, primeiramente, a seleção e a coleta de recortes textuais extraídos de fontes diversas ${ }^{3}$, compostos por anáforas diretas em Língua Portuguesa. Com esses textos pré-selecionados, submetemolos ao sujeito surdo nato, para a filmagem em Libras - tendo em vista essa necessidade de lidar com o surdo durante o processo de estudo, destacamos que o projeto foi enviado ao Comitê de Ética, o qual aprovou a realização da pesquisa no dia I I/o3/2016, por meio do parecer N. (CAAE) 53133816.0 .0000 .0107$.

Com as filmagens dos recortes textuais concluídos, o próximo passo foi anotá-las na interlíngua glosa-Libras, com auxílio do software ELAN (EUDICO - Linguistic Annotator). Adotamos o sistema de anotação dos sinais por meio de glosas proposto por Quadros e Pizzio (2007), pesquisadores da Universidade Federal de Santa Catarina - Brasil, sendo que aquilo que não compunha esse sistema foi acrescido por nós para atender às necessidades das anotações. Tal sistema é utilizado na anotação do Português para Libras a fim de aproximar o significado de um signo de uma língua na outra. Essa anotação facilita a análise dos fenômenos linguísticos na passagem de uma língua para outra (SANTOS, 20 I 2).

\footnotetext{
${ }^{3}$ Os recortes textuais foram coletados a partir de diversos gêneros textuais a fim de não haver uma motivação de um uso específico de determinada anáfora. Além disso, esse trabalho faz parte de uma pesquisa maior, direcionada pelo grupo "PORLIBRAS: fundamentos para a especificação, modelagem e implementação de Soluçôes Computacionais com vistas ao desenvolvimento de um sistema bilíngue de tradução automática Português-Libras”, o qual também fará uso desses recortes textuais aleatórios.
} 
Assim, os recortes textuais foram organizados de forma a constituir um Corpus Paralelo ${ }^{4}$ : temos, de um lado, as sentenças em Língua Portuguesa; de outro, as sentenças em glosa-Libras, para facilitar a comparação. Em outras palavras, o corpus foi agrupado a partir das categorias de anáforas diretas selecionadas em Português, a fim de verificar como a anáfora que ocorre nessa língua chega na Libras, a saber:

\section{Anáfora Direta/Correferencial}

I. Corpus Paralelo Português-Libras composto de anáfora pronominal na Língua Portuguesa. E na Libras, como fica?

2. Corpus Paralelo Português-Libras composto de anáfora por repetição na Língua Portuguesa. E na Libras, como fica?

3. Corpus Paralelo Português-Libras composto de anáfora sinonímica na Língua Portuguesa. E na Libras, como fica?

4. Corpus Paralelo Português-Libras composto de anáfora por hiperonímia na Língua Portuguesa. E na Libras, como fica?

5. Corpus Paralelo Português-Libras composto de anáfora por nomes genéricos na Língua Portuguesa. E na Libras, como fica?

6. Corpus Paralelo Português-Libras composto de anáfora por descrições definidas na Língua Portuguesa. E na Libras, como fica?

Com o Corpus Paralelo disponível, passamos, então, à verificação minuciosa ${ }^{5}$ de cada recorte textual, tanto numa língua, quanto na outra ${ }^{6}$. Inicialmente, analisamos as anáforas, na Língua Portuguesa, conforme os estudos realizados na perspectiva sociocognitivointeracional da Referenciação, pois foi esse o critério por nós escolhido para a seleção dos recortes textuais coletados.

${ }^{4}$ Adotamos como perspectiva metodológica a Linguística de Corpus (BERBER SARDINHA, 2003), tendo em vista a construção de um Corpus Paralelo, que consiste em dois textos (Língua Portuguesa e Libras).

sPara melhor compreensão, usamos alguns recursos gráficos e numéricos durante as análises. Os recursos utilizados destacam o referente e o elemento referencial, tanto na Língua Portuguesa quanto na Libras.

${ }^{6}$ Lembramos que para a primeira etapa - coleta do recorte textual em Língua Portuguesa -, os recortes textuais já foram previamente analisados, com vista à composição dos grupos anafóricos. 
Depois, o próximo passo foi analisar o referido fenômeno linguístico nas glosas-Libras, verificando a possível mudança de categoria, ou não, além da sua manutenção, ou não, baseado nas teorias estudadas, notadamente, em relação à perspectiva sociocognitivointeracional da Referenciação e à proposta de Pizzuto et al. (2006), referência nas Línguas de Sinais.

\section{Algumas análises}

Essa seção é dedicada à análise representativa do Corpus Paralelo Português-Libras o qual desenvolvemos durante a investigação (REIS, 2016, 2018, 2019). Tendo em vista o objetivo do trabalho, subdividimos as análises considerando as anáforas diretas elencadas como foco de partida na Língua Portuguesa: anáfora pronominal, anáfora por repetição, anáfora sinonímica, anáfora por hiperonímia, anáfora por nomes genéricos e anáfora por descrições definidas. Assim sendo, trazemos nesse momento, para efeito de ilustração, um exemplo de cada anáfora direta que constitui o Corpus em Língua Portuguesa (LP), a fim de verificar sua chegada em Libras.

Destacamos, tanto nos recortes textuais em Língua Portuguesa quanto nas glosas-Libras, o referente e o elemento referencial, para facilitar a visualização. O referente é destacado em itálico e sublinhado e o elemento referencial em itálico e em negrito. Sendo necessário, são usados outros recursos de realce. Vejamos, a seguir, as análises:

\section{Corpus Paralelo Português-Libras composto de anáfora direta pronomi- nal na Língua Portuguesa. E na Libras, como fica?}

Nesse instante, é nosso interesse observar como a anáfora direta por pronome em Língua Portuguesa se estabelece na Libras. A anáfora pronominal, na perspectiva da Referenciação, ocorre quando o enunciador usa um pronome como forma de retomar o referente já citado anteriormente: "acontece quando um pronome (pessoal ou demonstrativo) retoma um sintagma nominal” (HAAG; OTHERO, 2003, p. 68). Em seguida temos o quadro or, com sua respectiva análise. 


\begin{tabular}{|l|l|}
\hline Recorte Textual em Língua Portuguesa & Recorte Textual em glosa-Libras \\
\hline $\begin{array}{l}\text { (ı) Ana e Carlos estão namorando há } \\
\text { cinco anos e este ano eles ficaram noivos }\end{array}$ & (Ib) Ie < A-N-A >ld $\leq$ C-A-R-L-O-S $>$ \\
& COMEÇAR. (IX)EL@s2 COMEÇAR \\
& NOIVADO. \\
\hline
\end{tabular}

Quadro o - Corpus Paralelo Português-Libras: anáfora pronominal (Fonte: Autor da Pesquisa, 2019)

No recorte textual (ıa) em LP, há a presença dos referentes "Ana e Carlos”, os quais são retomados no desenrolar discursivo por meio de uma anáfora correferencial pronominal "eles”. Na tradução para a Libras, o sinalizante primeiro constrói o espaço referencial marcando cada referente em uma determinada posição: Ie $<$ A-N-A $>$; ld $<$ C-A-R-L-O-S $>$. O referente $<\mathrm{A}-\mathrm{N}-\mathrm{A}>$ é construído do lado esquerdo do sinalizante e $<\mathrm{C}$ A-R-L-O-S $>$ do lado direito. Ambos fixados a esses pontos específicos no espaço, disponíveis para o manejo referencial, o próximo passo foi retomálos, nesse caso, de uma só vez: (IX)EL@s2 (forma pronominal dual). Nessa glosa-Libras ( $\mathrm{r} b$ ), o surdo desenvolve o processo referencial por meio do apontamento realizado pela configuração de mão em $\mathrm{P}$, orientando a cabeça e os olhos em direção à localização em que os referentes $<\mathrm{A}-\mathrm{N}-\mathrm{A}>\mathrm{e}$ $<$ C-A-R-L-O-S $>$ foram construídas. A forma pronominal dual é, então, diretamente associada a esses pontos no espaço (QUADROS; PIZZIO; REZENDE, 2009). Temos nessa situação um processo referencial simultâneo: anáfora e dêixis, constituindo o dêitico-anafórico de classe padrão, empregado em dois momentos da glosa-Libras (Ib): a) (IX)EL@s2 NAMORAR s ANOS AQUI COMEÇAR; e b) (IX)EL@s2 COMEÇAR NOIVADO.

Quanto a esse processo simultâneo da anáfora e da dêixis, Schlenker (20I6) compreende que "[...] if the pronoun is used anaphorically, the antecedent typically establishes a locus, which is then índexed'(= pointed at) by the pronoun. The antecedent Noun Phrases are accompanied with pointing signs that establish the relevant loci” (SCHLENKER, 2016, p. 7). Consi- 
derando as questões analisadas, temos em ( $\mathrm{rb}$ ) o que denominamos neste trabalho de dêitico-anafórico pronominal dual.

A figura 02 apresenta a tela do programa Elan com o vídeo ( $\mathrm{I}$ b), considerando a glosa-Libras e a imagem em destaque:

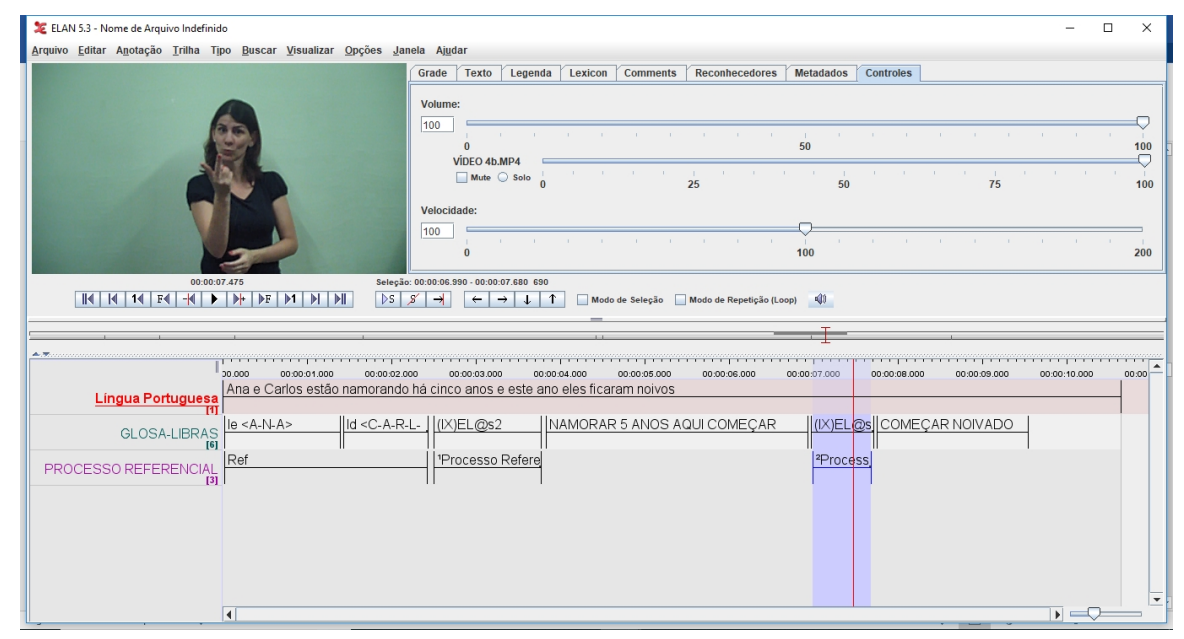

Figura o2 - Tela do Elan com o vídeo ib (Fonte: Elaborada pela pesquisadora.)

Corpus Paralelo Português-Libras composto de anáfora direta por repetição na Língua Portuguesa. E na Libras, como fica?

Nesta subseção, apresentamos e analisamos um exemplo do Corpus Paralelo Português-Libras composto, em LP, pela anáfora direta por repetição, ou conforme denominada por Haag e Othero (2003), anáfora correferencial cossignificativa. Há cossignificação porque ocorre a repetição lexical e o significado se mantém. Esse é um caso de correferência sem recategorização do referente. Seguindo a dinâmica anterior, temos um paralelo entre a LP e a Libras, a fim de constatar como esse fenômeno se desenvolve na língua brasileira de sinais. Vejamos: 


\begin{tabular}{|c|c|}
\hline Recorte Textual em Língua Portuguesa & Recorte Textual em glosa-Libras \\
\hline (2a) Minhas camisetas estão amassadas & CAMISETAS MINHAS \\
\hline Preciso passar essas camisetas urgentes. & $\begin{array}{l}\text { AMASSADAS. PRECISAR } \\
\text { PIDO (IX)ØPASSAR } \quad \text { (CL- ob- } \\
\text { ef<preocupad@>). }\end{array}$ \\
\hline
\end{tabular}

Quadro o2 - Corpus Paralelo Português-Libras: anáfora por repetição (Fonte: Autor da Pesquisa, 2019)

Nesse recorte textual representativo, em LP, o objeto do discurso ativado, "minhas camisetas", é retomado por meio do elemento referencial "essas camisetas". Assim sendo, podemos classificar que em (2a) há uma anáfora direta por repetição parcial do núcleo "camisetas". Já em (2b), na glosa-Libras, ocorre outro processo referencial: primeiramente, o referente é invertido "CAMISETAS MINHAS”, ordem disponível na Libras. Depois, quanto ao elemento referencial, esse sim sofreu mudança, pois o que antes era caracterizado como uma anáfora direta por repetição, na Libras transformou-se em um dêitico-anafórico, mediante o uso de uma estrutura altamente icônica/Transferência: (IX)ØPASSAR (CL- ob-ef<preocupad@>). Ou seja, o próprio ato de passar a roupa - marcado pelo verbo PASSAR (verbo classificador de instrumento, o qual apresenta a configuração de mão que representa a forma de segurar o instrumento para produzir a ação) -, atrelado ao olhar para baixo e à expressão facial, incorpora a retomada do referente. Conforme vimos, segundo Pizzuto et al. (2006), esse processo referencial exibe características que são marcadas por padrões específicos do olhar, por formas manuais que codificam atributos perceptíveis salientes das relações entre o referente e o elemento referencial, e por expressões faciais marcadas. Dessa forma, quando o sujeito surdo utiliza esse dêitico-anafórico, ele não o faz aleatoriamente, ao contrário, ele tem a intenção de descrever a situação, em uma perspectiva tridimensional. Há em sua escolha finalidades comunicativas, as quais podem ser reveladas a partir de conhecimen- 
tos culturalmente compartilhados pelos usuários da Língua de Sinais. Nessa perspectiva, temos então um dêitico-anafórico por EAI/Transferência.

$\mathrm{Na}$ figura a seguir, podemos ver a tela do programa Elan com o vídeo (2b) e seus constituintes:

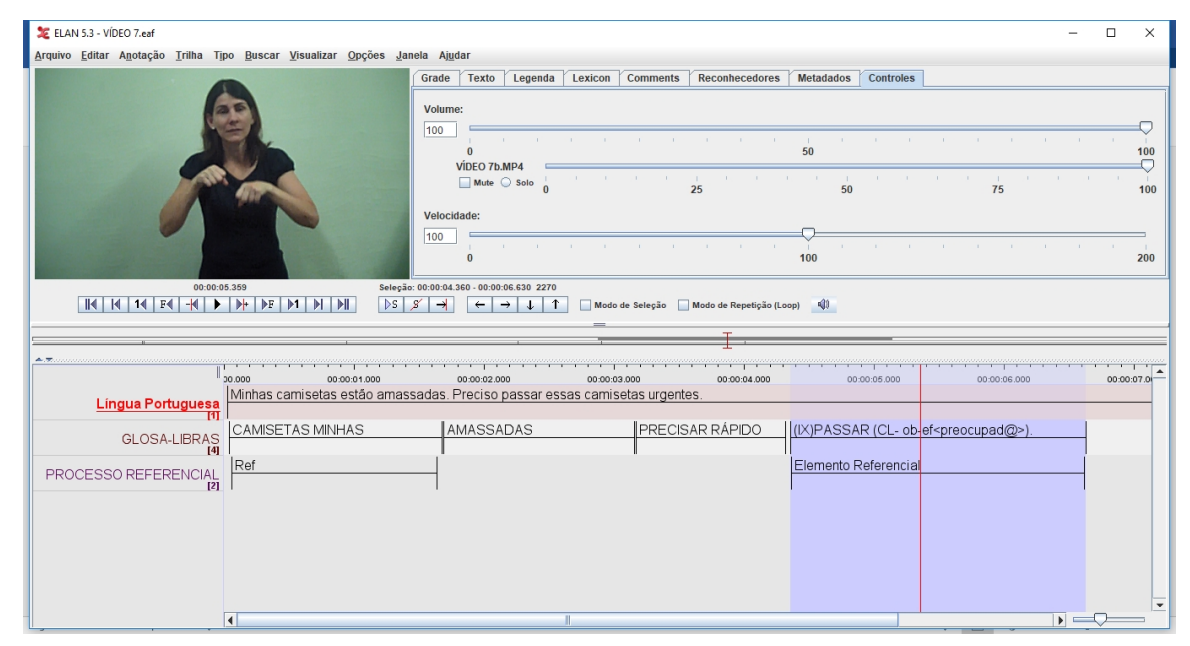

Figura 3 - Tela do Elan com o vídeo (2b) (Fonte: Elaborada pela pesquisadora).

Corpus Paralelo Português-Libras composto de anáfora direta sinonímica na Língua Portuguesa. E na Libras, como fica?

Nesse momento nos concentramos em analisar um recorte textual referente à anáfora correferencial por sinonímia. De acordo com Koch (2004), “a seleção de um sinônimo adequado para fazer a remissão é determinada tanto pelo gênero textual como pela variedade de língua utilizada, ou até mesmo por uma opção estilística do enunciador" (KOCH, 2004, p. 246). Por essa razão, pesquisadores da área dizem que essa é uma anáfora correferencial sem recategorização. Ao examinarmos o recorte textual selecionado, observamos se essa anáfora presente no Português se mantém ou não na Libras, bem como se assume outra categoria referencial. Observemos: 


\begin{tabular}{|c|c|}
\hline Recorte Textual em Língua Portuguesa & Recorte Textual em glosa-Libras \\
\hline $\begin{array}{l}\text { (3a) A professora tenta ensinar matemáti- } \\
\text { ca para o menino. } \\
\text { - Se eu te der quatro chocolates hoje e } \\
\text { mais três amanhã, você vai ficar com... } \\
\text { com... com...? } \\
\text { E o garoto: } \\
\text { - Contente! }\end{array}$ & 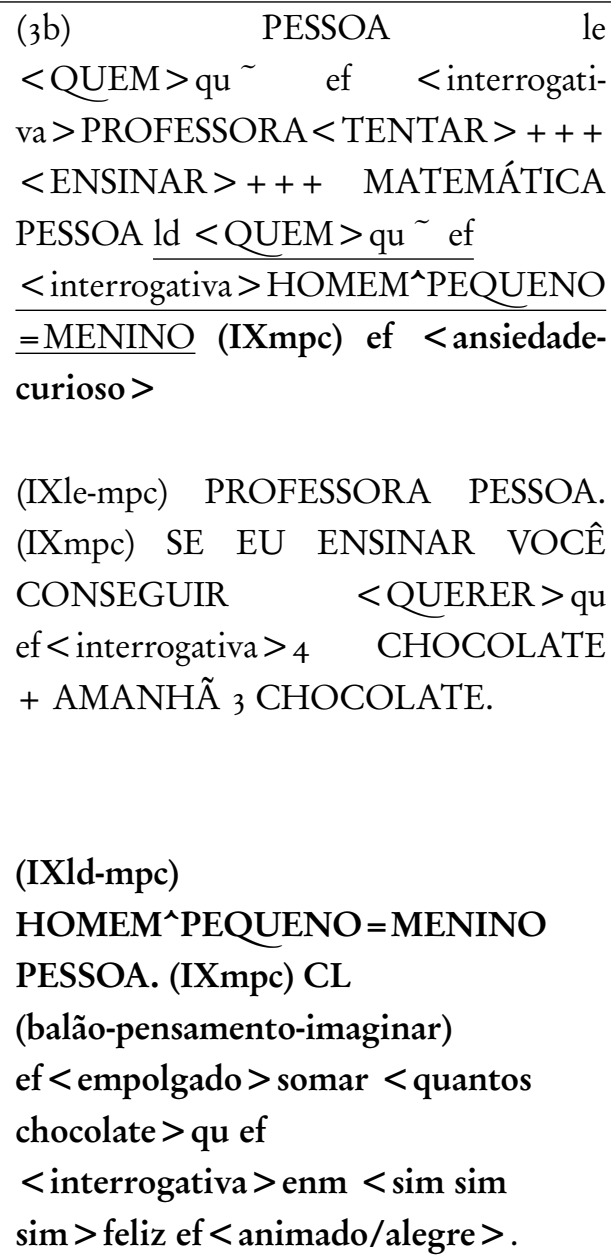 \\
\hline
\end{tabular}

Quadro 03 - Corpus Paralelo Português-Libras: anáfora sinonímica (Fonte: Autor da Pesquisa, 20 I9)

No recorte textual (3a), temos uma 'piada', caracterizada como um texto narrativo curto de final engraçado, cujo objetivo é provocar risos em quem lê. Para a adequada compreensão do efeito de humor do referente em destaque no recorte textual (3a), o interlocutor precisa conhecer minima- 
mente as possíveis situações que se passam no ambiente escolar: esse é o 'típico' menino/aluno que estabelece uma interpretação do que a professora diz conforme o que lhe convém. Em (3a), o referente "o menino", em LP, é retomado por uma anáfora correferencial sinonímica "o garoto". Na tradução para a Libras, o surdo necessitou primeiramente compreender que se tratava do gênero discursivo piada, o que requer também identificar o efeito de humor provocado pelo texto. Com essa compreensão, o próximo passo foi traduzir o recorte textual para a Libras. O surdo usou o recurso de 'Troca de Papéis', ou, conforme alguns autores denominam, 'Mudança de Postura Corporal', 'Ação Construída', fenômeno conhecido como 'Role Shift', bastante comum nas línguas visuoespaciais quando se trata de narrativas. Esse fenômeno é considerado por Cormier et al. (2O I 5 ) como "a representational device where one or more bodily articulators (including the head, face, eyegaze, arms, and torso) are used to represent the utterances, thoughts, feelings and/or actions of one or more referents" (CORMIER et al., 2OI s, p. I67).

Em (3b), na glosa-Libras, o referente é PESSOA ld <QUEM $>$ qu ef $<$ interrogativa $>\mathrm{HOMEM}^{\wedge} \mathrm{PEQUENO}=\mathrm{MENINO}$ ef $<$ ansiedade $>$, posicionado do lado direito do espaço de sinalização, já orientando para o recurso que será usado no processo de retomada. Após demarcar o referente no espaço discursivo, tem-se a primeira retomada, realizada pelo Role Shift: (IXmpc) ef < ansiedade-curioso>. Nessa reconstrução do referente, o surdo já incorpora a personagem, atribuindo-lhe características físicas (como expressões faciais e corporais etc.) e psicológicas (como alegria, animação etc), coerentes com a atitude do objeto do discurso. Temos, nesse caso, um dêitico-anafórico de classe de complexas unidades manuais e não manuais, marcado por padrões específicos do olhar, por formas manuais que codificam atributos perceptíveis salientes das relações entre o referente e o elemento referencial, por expressões faciais marcadas e 
por modificações da cabeça, dos ombros e do tronco, tipicamente identificadas como 'recursos de troca de papeis' (PIZZUTO et al., 2006). Neste trabalho, denominamos esse processo referencial como dêitico-anafórico por EAI/Transferência. Em um segundo momento, na construção da cadeia discursiva, localizamos uma retomada no instante da troca de papeis: (IXldmpc) $\mathrm{HOMEM}^{\wedge} \mathrm{PEQUENO=MENINO} \mathrm{PESSOA.} \mathrm{"O} \mathrm{usuário} \mathrm{da} \mathrm{Libras}$ retoma o referente apenas mudando a posição do seu corpo" (FERREIRA BRITO, 20Io). Por fim, temos a terceira retomada também por Role Shift: (IXmpc) CL (balão-pensamento-imaginar) ef $<$ empolgado $>$ somar $<$ quantos chocolate $>$ qu ef $<$ interrogativa $>$ enm $<$ sim $\operatorname{sim} \operatorname{sim}>$ feliz ef $<$ animado/alegre $>$. Tanto os sinais manuais quanto as expressões faciais e corporais realizadas nesse momento caracterizam a personagem, e não o enunciador. Nesse sentido, Cabeza e García-Miguel (20 I 8) defendem que “los señantes adaptan a sus propósitos comunicativos las posibilidades de construcción que les ofrecen tanto las articulaciones manuales y los articuladores no manuales (en la elaboración de la acción construida)" (CABEZA; GARCÍA MIGUEL, 201 8, p. 258). Por todas essas questões destacadas, denominamos esse processo referencial como dêitico-anafórico por EAI/Transferência.

$\mathrm{Na}$ figura 04, é possível visualizar a tela do programa Elan referente ao vídeo (3b), em um dos momentos nos quais se incorpora o referente:

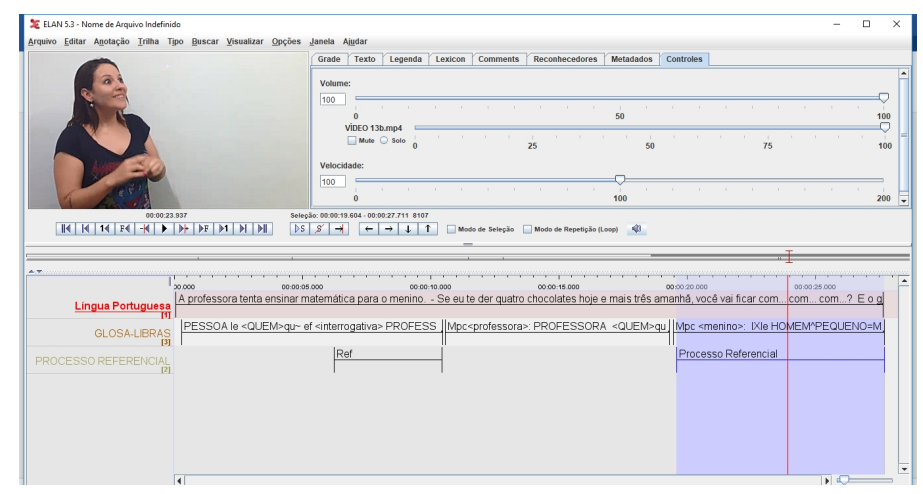

Figura 04 - Tela do Elan com o vídeo 3b (Fonte: Elaborada pela pesquisadora). 


\section{Corpus Paralelo Português-Libras composto de anáfora direta por hipe- ronímia na Língua Portuguesa. E na Libras, como fica?}

Nesta subseção, analisamos um recorte textual composto pela anáfora direta com recategorização por hiperonímia, em LP, com intenção de observar como esse processo anafórico se comporta na Libras. O hiperônimo, quando assume papel anafórico, "pode ter a função de retomar um termo pouco usual, atualizando, assim, os conhecimentos do interlocutor" (KOCH; ELIAS, 2006, p. I4I). Vejamos:

\begin{tabular}{|l|lll|}
\hline Recorte Textual em Língua Portuguesa & Recorte Textual em glosa-Libras \\
\hline (4a) Os biólogos avistariam um réptil no & $(4 \mathrm{~b})$ BIÓLOG VER I & CL (animal \\
rio, mas depois assustaram o animal na & rastejando^vários=réptil) & \\
margem. & ÁGU^CAMINHO=RIO. & \\
& IX(EL@) & JACARÉ & SUSTO \\
& ef<assustado $>$ AFUNDOU & \\
& ÁGU^CAMINHO=RIO. & \\
\hline
\end{tabular}

Quadro 04 - Corpus Paralelo Português-Libras: anáfora por hiperonímia (Fonte: Autor da Pesquisa, 2019)

O recorte textual (4a), na LP, é composto pelo referente "um réptil”, o qual é retomado por meio de uma anáfora correferencial por hiperonímia. Nesse sentindo, "um réptil" é o hipônimo e "o animal” é o hiperônimo, em uma relação semântica, em que "o animal" abarca todos os traços lexicais de "um réptil". Na glosa-Libras (4b), percebemos um processo referencial inverso: o surdo constrói no espaço discursivo o objeto do discurso CL (animal-rastejando^vários = réptil), por meio de um classificador de entidade, conforme Supalla (1982). Esse referente é representado, nesse contexto, pela configuração de mão 36, com movimentos de animal rastejando, caracterizando um RÉPTIL, o qual é retomado por IX(EL@) JACARÉ. Esse processo referencial é composto por um pronome, com apontamento manual pela configuração de mão em $\mathrm{G}$, com orientação do olhar para o espaço 
de sinalização onde o referente foi construído, especificando-o por meio do sinal JACARÉ. Nesse processo referencial há uma especificação ou refinamento de uma categorização por meio da sequência hiperônimo/hipônimo. Em outras palavras, diferente do que aconteceu em (4a), na LP, na Libras, em (4b), o surdo lança primeiro o hiperônimo "RÉPTIL", termo mais genérico, o qual é em seguida retomado por um dêitico-anafórico de classe padrão atrelado a um hipônimo, termo mais particular: "IX(EL@) JACARÉ”. Nesse caso, denominamos esse processo referencial como dêitico-anafórico pronominal especificador.

Podemos ver, na figura os, a tela do Elan com o vídeo (4b), composta pela imagem congelada do apontamento manual e visual, que compõe o processo referencial em evidência:

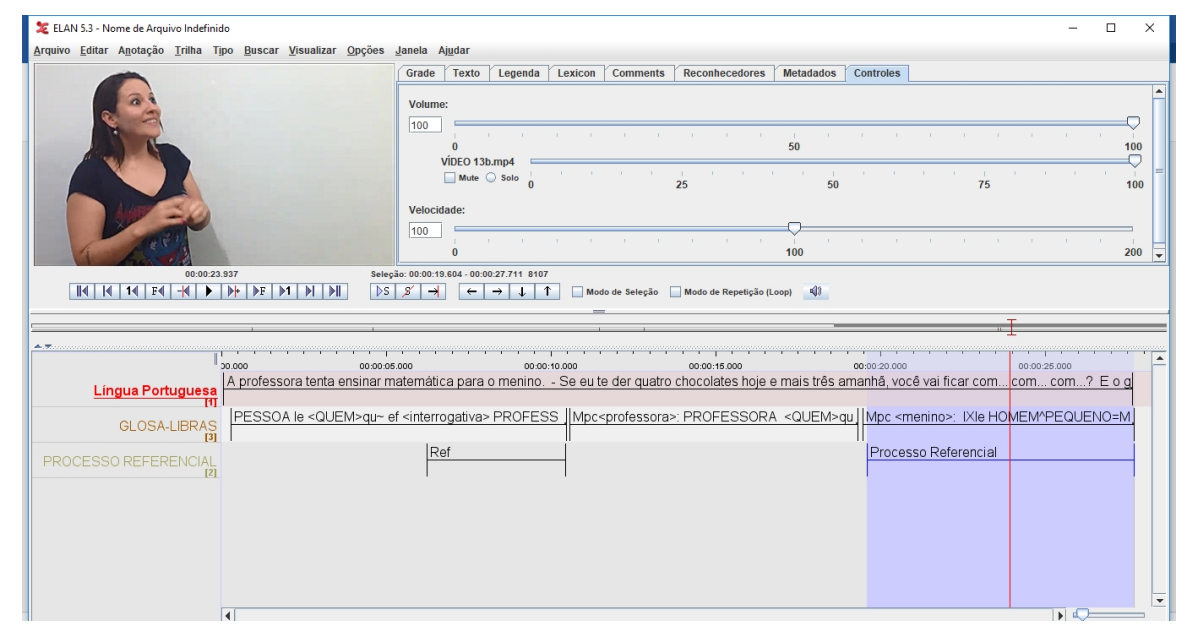

Figura os - Tela do Elan com o vídeo 4b (Fonte: Elaborada pela pesquisadora).

Corpus Paralelo Português-Libras composto de anáfora direta por nomes genéricos na Língua Portuguesa. E na Libras, como fica?

Neste momento, apresentamos e analisamos um exemplo do Corpus Paralelo Português-Libras composto pela anáfora correferencial com recategorização por nomes genéricos na LP, com o objetivo de observar como 
esse processo anafórico se comporta na Libras. "Os termos genéricos têm a função de retomar de maneira ampla e geral os elementos linguísticos que o antecedem na superfície textual” (BERNARDI, 201 2, p. 6i). Observemos a seguir:

\begin{tabular}{|c|c|}
\hline Recorte Textual em Língua Portuguesa & Recorte Textual em glosa-Libras \\
\hline $\begin{array}{l}\text { (sa) Meu avô tinha uma coleção de vin- } \\
\text { hos antigos. Era o negócio que ele mais }\end{array}$ & $\begin{array}{lr}(s \mathrm{~b}) & \text { VINHO CL le } \\
\text { (coleção-vinhos }+++ \text { ef } & \text { interessante }>\text { ) }\end{array}$ \\
\hline aprec & $\begin{array}{l}\text { ANTIGOS AVÔ TER. (IX) CL le } \\
\text { (est@ coleção-vinhos+++) BEBIDA } \\
\text { AVÔ (IX)ØAPRECIAR-DEGUSTAR } \\
\text { ef< gostoso/bom > MAIS. }\end{array}$ \\
\hline
\end{tabular}

Quadro os - Corpus Paralelo Português-Libras: anáfora por nome genérico (Fonte: Autor da Pesquisa, 2019)

O recorte textual (sa) é composto em LP pelo objeto do discurso "uma coleção de vinhos antigos". Esse referente é recategorizado pela forma nominal "o negócio", caracterizando, desse modo, uma anáfora correferencial por nome genérico. $\mathrm{Na}$ glosa-Libras $(5 \mathrm{~b})$, o referente é marcado no espaço como VINHO CL (le coleção-vinhos +++ ef < interessante $>$ ) ANTIGOS. Após o sinal VINHO, o tradutor ilustrou no espaço uma adega de vinho, por meio de um classificador descritivo, que representa a forma e o tamanho do elemento em questão: CL (le coleção-vinho +++ ef < interessante $>$ ). Com esse referente construído, mais adiante houve então sua retomada por meio do classificador já representado no espaço, do lado esquerdo do sinalizante, acoplado ao sinal BEBIDA: (IX) CL le (est@ coleção-vinhos + + +) BEBIDA. É relevante destacar que, na retomada desse classificador descritivo, o surdo o faz atrelado ao pronome demonstrativo, em outras palavras, o tradutor aponta para o ponto de construção do referente e com a configuração de mão em G já ilustra a adega, fazendo, portanto, construções simultâneas. 
Dando sequência à cadeia referencial, logo a seguir, o verbo (IX)ØAPRECIAR-DEGUSTAR ef < gostoso/bom $>$, junto com olhar específico e expressão facial marcada, retomam BEBIDA, que remete automaticamente ao referente em evidência. Esse conjunto sequêncial de retomadas ilustrativas visam, a nosso ver, a reforçar e a destacar o objeto de discurso em questão, deixando-o sempre saliente no espaço de sinalização. Nessa perspectiva, consideramos esse processo referencial como um dêitico-anafórico de classe de complexas unidades manuais e não manuais, pois diferentes subtipos de EAIs/Transferências são combinadas entre si, com sinais padrão também, para codificar simultaneamente informações voltadas ao referente, permitindo uma especificação multilinear do processo referencial dêitico-anafórico (PIZZUTO et al., 2006). Assim sendo, temos então em (sb) um dêiticoanafórico por EAI/Transferência.

$\mathrm{Na}$ figura 06 , podemos ver a tela do Elan com vídeo (sb), considerando as trilhas construídas:

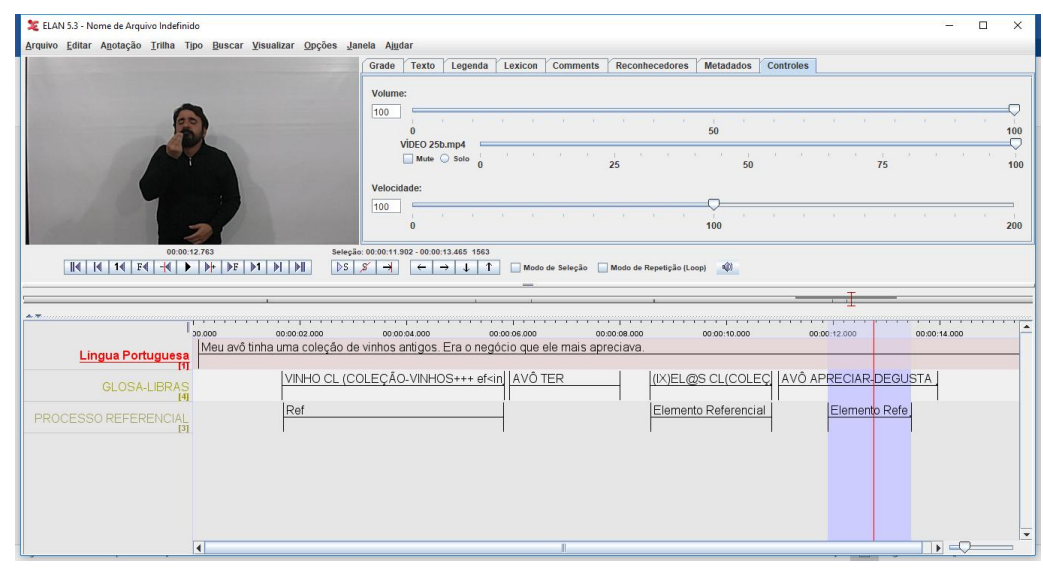

Figura o6 - Tela do Elan com o vídeo sb (Fonte: Elaborada pela pesquisadora).

Corpus Paralelo Português-Libras composto de anáfora direta por descrições definidas na Língua Portuguesa. E na Libras, como fica? 
Esta parte é reservada à análise da anáfora correferencial com recategorização por descrição definida na LP, a fim de observar, no Corpus Paralelo Português-Libras, como esse processo anafórico chega na Libras. Segundo Koch e Elias (2006), tais anáforas "desempenham uma série de funções cognitivo-discursivas de grande relevância na construção textual do sentido" (KOCH; ELIAS, 2006, p. I 37). Vejamos:

\begin{tabular}{|l|l|}
\hline Recorte Textual em Língua Portuguesa & Recorte Textual em glosa-Libras \\
\hline (6a) O filme Central do Brasil fez muito su- & (6b) FILME NOME <C-E-N-T-R-A-L D- \\
cesso. O clássico do cinema nacional levou & O B-R-A-S-I-L> PASSADO SUCESSO. \\
a atriz Fernanda Montenegro a concorrer & (IX)FILME ESS PROMOVER MUL- \\
ao Oscar em I 999. & HER ATRIZ <F-E-R-N-A-N-D-A M-O- \\
& N-T-E-N-E-G-R-O > TROFÉU <O-S-C- \\
& A-R > I999 CONCORRER. \\
\hline
\end{tabular}

Quadro o6 -Corpus Paralelo Português-Libras: anáfora por descrição nominal definida (Fonte: Autor da Pesquisa, 2019)

O recorte textual (6a), em LP, é composto pela presença do objeto do discurso "O filme Central do Brasil". Na sequência, esse referente é retomado mediante a uma descrição nominal definida "o clássico do cinema nacional”, com a intenção de situar o interlocutor sobre a relevância desse filme "Central do Brasil" no contexto brasileiro. O uso de uma descrição nominal com papel de recategorização de objeto do discurso "implica sempre uma escolha entre uma multiplicidade de formas de recategorizar o referente, escolha esta que será feita, em cada contexto, segundo a proposta de sentido do produtor do texto" (KOCH, 2005, p. 35). Na glosa-Libras (6b), o sujeito surdo, ao traduzir o recorte textual, construiu o seguinte objeto do discurso: "FILME NOME <C-E-N-T-R-A-L D-O B-R-A-S-I-L>". É possível observar que esse referente é realizado com o auxílio da datilologia relativa ao substantivo próprio, deixando-o mais evidente ao seu interlocutor. Esse objeto do discurso é, na sequência, retomado mediante a repetição 
do sinal "FILME", atrelada ao pronome demonstrativo "ESS@”, que é caracterizado pelo apontamento manual e visual, no espaço de sinalização, gerando um dêitico-anafórico de classe padrão: “FILME ESS@”. Landaluce (20 I 5) consente que nas línguas de sinais "es muy común que los mismos demostrativos, locativos y deícticos temporales usados deícticamente se usen también anafóricamente" (LANDALUCE, 201 s, p. 42). Por todos esses elementos, o processo referencial em (26b) pode ser caracterizado como um dêitico-anafórico cossignificativo pronominal. Vale destacar que essa retomada na Libras foi bastante objetiva, não considerando o fato de o filme ser um "clássico do cinema brasileiro", conforme enfatizado no recorte textual da LP. Na figura a seguir, observa-se a tela do programa Elan referente ao vídeo (6b) e aos seus constituintes:

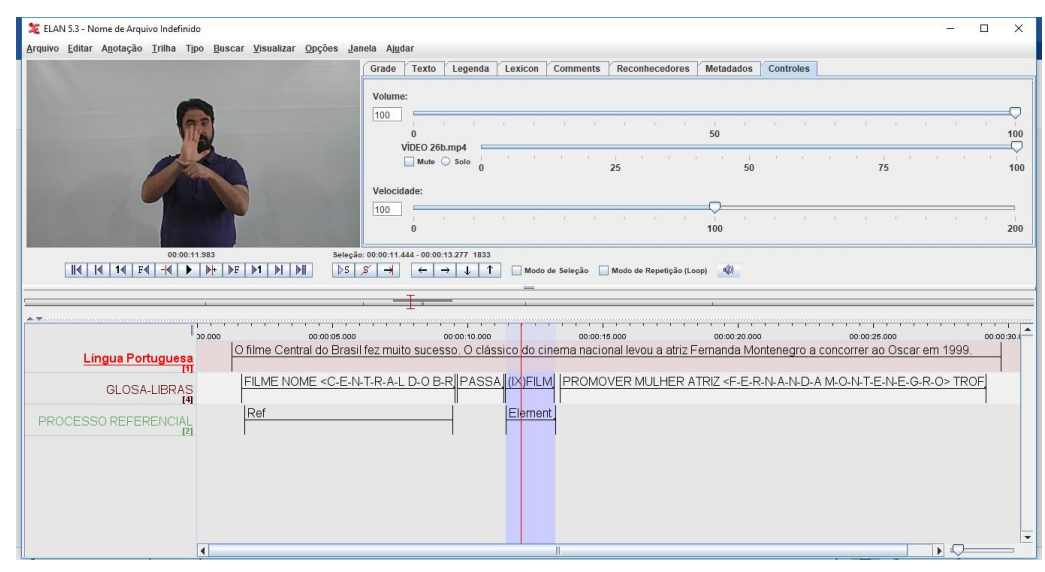

Figura 07 - Tela do Elan com o vídeo 6b (Fonte: Elaborada pela pesquisadora).

\section{ConsideraÇÕES Finais}

As análises das glosas-Libras apresentaram características da própria língua na constituição do processo referencial, considerando, por exemplo, o uso simultâneo entre a anáfora e a dêixis no espaço de sinalização - retomar e apontar para o ponto específico em que o referente foi construído. 
Assim, o processo referencial mais recorrente nas glosas-Libras foi o dêiticoanafórico de classe padrão. Sua recorrência foi creditada, a nosso ver, à própria modalidade da Libras que, entre outros fatores, constitui, no espaço discursivo, ponto específico para o referente. Ou seja, os elementos introduzidos no discurso geralmente são associados a pontos referenciais no espaço da sinalização. Tivemos também nas glosas-Libras a constante presença do dêitico-anafórico de classe de complexas unidades manuais e não manuais, que se mostrou como uma forma consciente do sinalizante em ilustrar o que se diz, sendo então carregado de operações discursivas e cognitivas, por meio das quais os sinalizantes transferem sua concepção do mundo real para o mundo tetradimensional do discurso sinalizado.

Os dêiticos-anafóricos de classe padrão, assim como os de dêiticosanafóricos de classe de complexas unidades manuais e não manuais, advindos nas glosas-Libras, mostraram-se estratégias fundamentais para a condução da cadeia referencial na Libras. Quando o sujeito surdo utilizou determinado processo referencial, ele não o fez aleatoriamente, ao contrário, havia em sua escolha finalidades comunicativas, as quais podem ser reveladas a partir de conhecimentos culturalmente compartilhados pelos usuários da línguas de sinais, em um processo discursivo. Com a análise do Corpus Paralelo Português-Libras foi possível perceber como a anáfora que sai da LP, num viés tradutório, pode chegar na Libras, considerando as estratégias de construção de cadeias referenciais específicas da modalidade visuoespacial. Partindo da perspectiva da Referenciação como uma prática discursiva, marcada por situações sociocognitivas e interacionais, torna-se indispensável destacar a simultânea relação entre a anáfora e a dêixis presente nas glosas-Libras analisadas, contribuindo para a construção dos sentidos na Libras, e representando dinamicidade e a fluidez entre os processos referenciais. É nesse ponto que os estudos de Referenciação e de dêitico-anafórico nas LSs se cruzam e assumem um papel importante para o desenvolvimento das cadeias 
referenciais na Libras. Nessa perspectiva, concluímos que as análises realizadas proporcionam evidências importantes sobre o processo referencial na Libras.

\section{REFERÊNCIAS}

A pothéloz, Denis. Papel e funcionamento da anáfora na dinâmica textual. In: Calvacante, M. M.; Rodrigues, B. B.; Ciula, A. (Orgs.). Referenciação. São Paulo: Contexto, 2003.

A pothéloz, Denis; Reichler-Beguelin, M. J. Interpretations and functions of demonstrative NPs in indirect anaphora. Journal of Pragmatics, $\mathrm{n}^{\circ}$ 3, p.363-97, mar. 1999.

Bellugi, U.; Klima, E. S. The acquisition of three morphological systems in: American Sign Language. Papers and Reports on Child Language Development 2 I, I-35. Palo Alto, CA: Stanford University Press, 1982.

Bernardi, Eviliane. Análise do processo anafórico em textos produzidos por alunos do terceiro ano do ensino médio de uma escola pública de Cascavel - PR. i4sf. Dissertação (Mestrado em Letras). Universidade Estadual do Oeste do Paraná - Cascavel, 20 I 2.

Berber Sardinha, Tony. Uso de corpora na formação de tradutores. D.E.L.T.A. i g: Especial, p. 43-70. 2003.

BRASIL. Decreto $n^{o} 5.626$ de 22 de dezembro de 2005 . - Regulamenta a Lei ${ }^{\circ}{ }_{1} 0.436$ de 24 de abril, que dispõe sobre a Língua Brasileira de Sinais.

BRASIL. Lei $n^{\circ}$ I0.436. Presidência da República, dispõe a Língua Brasileira de Sinais - LIBRAS. Brasília, 24 de abril de 2002.

Buhler, K. Teoría del lenguaje (Traducido por Julián Marías). Madrid. Alianza Editorial, i 979.

Cabeza, Carmen; Garcî́a-Miguel, José. Verbalización de eventos de movimiento y localización en lengua de señas española (LSE): un análisis de las construcciones descriptivas con clasificador de entidad. In: ONOMÁZEIN, 4I, 2018.

Cavalcante, Monica. Referenciação: sobre coisas ditas e não ditas. Fortaleza: Edições UFC, 20 I I.

Ciulla, Alena. Os processos de referência e suas funções discursivas: o universo literário dos contos. 2008. 2orf. Tese (Doutorado em Linguística). Centro de Humanidades, Universidade Federal do Ceará, Fortaleza, 2008.

Colamarcao, M. Referenciação e construção de sentido nas fábulas de Monteiro Lobato e Esopo. Tese (Doutorado em Língua Portuguesa). Universidade Federal do Rio de Janeiro, Rio de Janeiro, 2014.

Cormier, K. et al. Rethinking Constructed Action. Sign Language E Linguistics, I 8 (2), 2015.

Cuxac, C. La Langue des Signes Française (LSF). Les voies de l'iconicité. Faits de Langues, p. i 5- 16. Paris, 2000.

Felipe, Tanya. Políticas públicas para inserção da Libras na educação de surdos. In. Revista Espaço. Informativo Técnico Científico do INES. $\mathrm{N}^{\circ}$ 25/26, JAN-DEZ./2006, p. 33- 47.

Ferreira Brito, Lucinda. [1995]. Por uma Gramática de Línguas de Sinais. Rio de Janeiro: Tempo Brasileiro, 20 го.

Friedmann, L. On the semantics of space, time and person in American Sign Language. Language SI, p. 940-96I, I975.

HaAg, C. R; Othero, G. de Á. Anáforas associativas nas análises das descrições definidas. ReVEL - Revista Virtual de Estudos da Linguagem, v. I, n. I, p. I-16, ago. 2003. Disponível em: $<$ www.revel.inf.br >. Acesso em: io set. 2016.

Kосн, Ingedore Grunfeld Villaça; Elias, Vanda Maria. Ler e compreender: os sentidos do texto. São Paulo: Contexto, 2006.

$\mathrm{KoCH}$, Ingedore Grunfeld Villaça. Referenciação e orientação argumentativa. In: $\mathrm{KoCH}$, Ingedore Grunfeld Villaça; Morato, Edwiges Maria; Bentes, Anna Christina (Orgs.). Referenciação e Discurso. São Paulo: Contexto, 2005, p. 33-45. 
KoCH, Ingedore Grunfeld Villaça. Linguagem e cognição: a construção e reconstrução de objetosde-discurso. Veredas - Revista de Estudos Linguísticos, Juiz de Fora, v. 6, n. I, p. 29-42, 2004 .

Koch, Ingedore Grunfeld Villaça. Argumentação e linguagem. São Paulo: Cortez, 2002.

$\mathrm{KoCH}$, Ingedore Grunfeld Villaça; MarCuSCHI, Luiz Antônio. Processo de referenciação na produção discursa. DELTA - Revista de Documentação de Estudos em Linguística Teórica e Aplicada, São Paulo, v. I4, n. especial, p. ı69-190, I998.

Landalu CE, J. F. La deixis en la Lengua de Signos Española (LSE): Efectos de la modalidad espaciovisual. Tesis (Doctorado en Lengua). Universidad del País Vasco, 20 i 5.

LEAL, Christiana Lourenço. Estratégias de referenciação da produção escrita de alunos surdos. Rio de Janeiro: UFRJ/Faculdade de Letras, 20 I . Tese (doutorado) - UFRJ/ Faculdade de Letras/ Programa de Pós-graduação. Disponível em: http://www.letras.ufrj.br/posverna/ doutorado/LealCL.pdf. Acesso em: io set. 20 is.

Mondada, Lorenza; Dubois, Danièle. Construção dos objetos de discurso e categorização: uma abordagem dos processos de referenciação. In: CAVALCANTE, Mônica; RODRIGUES, Bernardete; CIULlA, Alena (Orgs.). Referenciação. São Paulo: Contexto, 2003. (Coleção Clássicos da Linguística).

Mondada, Lorenza; Dubois. Construction dês objets de discurs et catégorisation: une approche dês processos de référentiation. TRANEL. Vol. 23. Neuchâtel. Institute de Linguistique de IUnivesité de Neuchâtel. 1995. p. 273-302.

Morais, M. A. Referenciação em campo: a construção de sentidos nas notícias esportivas. Tese (Doutorado em Língua Portuguesa). Universidade Federal do Rio de Janeiro, Rio de Janeiro, 2014.

Pizzuto, Elena; Rossini, Paolo; Sallandre, Marie-Anne; WILKINSON, Erin. Dêixis, anáfora e estruturas altamente icônicas: evidências interlinguísticas nas línguas de Sinais Americana (ASL), Francesa (LSF) e Italiana (LIS). In: QUADROS, Ronice Müller de; VASCONCELLOS, Maria Lúcia Barbosa (Orgs. e Trad.). Questões teóricas das pesquisas em língua de sinais. Editora Arara Azul. Petrópolis, 2006. Disponível em: http://www.editora-arara-azul. com.br/ebooks/catalogo/36.pdf. Acesso em: I 2 out. 2016.

Quadros, R. M. de; Pizzio, A. L.; Rezende, P. L. F. Lingua Brasileira de Sinais IV: Tópicos de linguística aplicados à Língua de Sinais - Uso do espaço e sistemas de transcrição (ELAN). Universidade Federal de Santa Catarina (UFSC): Florianópolis. 2009. Apostila. Disponível em: http://www.libras.ufsc.br/colecaoLetrasLibras/eixoFormacaoEspecifica/linguaBrasile iraDeSinaisII/assets/482/Lingua_de_Sinais_IV_para_publicacao.pdf. Acesso em: Is set. 2015.

Quadros, R. M. de; PIZZIO, A. L. Áquisição da língua de sinais brasileira: constituição e transcrição dos corpora. In: SALLES, H. (Org.) Bilinguismo e surdez. Questões linguísticas e educacionais. Goiânia: Cânone Editorial, 2007.

ReIs, Leidiani da Silva. O Processo Referencial na Libras face às Ocorrências Anafóricas em Lingua Portuguesa. Tese de Doutorado, Universidade Estadual do Oeste do Paraná (UNIOESTE), 2019.

Reis, Leidiani da Silva; Bidarra, Jorge. Anáfora na Língua Brasileira de Sinais: uma proposta de categorização. Documentos de Traballo en Ciencias da Linguaxe, v. I, p. I-44, 20 I 8.

Reis, Leidiani da Silva; Bidarra, Jorge. A anáfora na interface Português-Libras. In: Revista Interletras. Dourados - MS, v. 6, n. 24, 2016.

SAntos, L.; CAVALCANTE, M. Referenciação: continuum anáfora-dêixis. Intersecções, Jundiaí, v. I 2, n. I, maio. 2014.

Santos, Renata Souza. Os gêneros discursivos em livro didático para surdos: análise dos procedimentos tradutórios aplicados de português para Libras. In: ALBRES, Neiva de Aquino; SANTIAGO, Vania de Aquino. Libras em estudo: tradução/interpretação. São Paulo: FENEIS, 2012.

SChlenker, Philippe. Conditionals as definite descriptions: a referential analysis. Research on Language and Computation, 2016. 
Slomski, V. Geni. Educação Bilíngue para surdos: concepções e implicações práticas. 2.ed. Curitiba: Juruá, 2012.

Stokoe, Willian. Sign Language Structure: An outline of the visual communication systems of the American deaf. Studies in Linguistics. O.P.8, 1960.

SupAll, T. R. Structure and acquisition of verbs of motion and location in American Sign Language. Ph.D. thesis, University of California, San Diego, 1982.

recibido: julio de 2019 aceptado: octubre de 2019 